\title{
Políticas públicas e direitos sociais de trabalhadoras rurais: caso da associação Amabela, Pará
}

Public policies and social rights of female rural workers: case of the Amabela association, Pará

\author{
Maria Zilomar de Sousa Uchôa ${ }^{1}$ \\ Carla Ramos $^{2}$ \\ Lidiane Nascimento Leão ${ }^{3}$ \\ Thiago Almeida Vieira ${ }^{4}$
}

\begin{abstract}
Resumo:
O artigo apresenta os resultados de uma pesquisa sobre o acesso aos direitos sociais por mulheres associadas a uma organização social rural. Para isso, foram entrevistadas 20 sócias que fazem parte da Associação de Mulheres Trabalhadoras Rurais do Município de Belterra-Pará (AMABELA), nos meses de abril a maio de 2019 , visando analisar os direitos sociais que elas tinham acesso. Os dados foram submetidos à Análise de Conteúdo. Para a concretização desses direitos dentro da associação, é necessário a implementação de políticas públicas direcionadas às necessidades sociais daquelas mulheres. É imperativo que o poder público desenvolva uma postura ativa diante dessa necessidade social, tornando-as mais abrangentes a ponto de atender todas as pessoas que fazem parte daquela associação e ou das comunidades rurais da região. Assim, esperam-se políticas extensivas e igualitárias devem ser propostas, discutidas e executadas intentando respeitar a dignidade da pessoa humana. Em termos de organização, essas políticas precisam também valorizar o processo de organização social das agricultoras, proporcionando inclusão dentro da associação e o interesse de outras mulheres das comunidades a se associarem na AMABELA. Os movimentos sociais femininos são responsáveis pelas informações de seus direitos.
\end{abstract}

Palavras-Chave: Amazônia; Direitos sociais; mulheres; organização social.

\begin{abstract}
:
This paper presents the results of a survey on access to social rights by women associated with a rural social organization. Thus, 20 members who are part of the Association of Rural Women Workers of the Municipality of Belterra-Pará (AMABELA) were interviewed from April to May 2019, to analyze the social rights they had access to. Data were submitted to Content Analysis. For the realization of these rights within the association, it is necessary to implement public policies
\end{abstract}

\footnotetext{
${ }^{1}$ Mestra em Sociedade, Ambiente e Qualidade de Vida. E-mail: maria.uchoa@ufopa.edu.br

2 Antropóloga. Doutora pela Universidade do Texas (at Austin). Professora do PPGCS do Instituto de Ciências da Sociedade (ICS). E-mail: carla.ramos@ufopa.edu.br

3 Advogada. Doutora em Direito pela Universidade de São Paulo. Professora do PPGCS do Instituto de Ciências da Sociedade (ICS). E-mail: lidiane.leao@ufopa.edu.br

4 Pós-Doutor pela Universidade do Algarve. Doutor em Ciências Agrárias. Docente da Ufopa: IBEF, PPGSAQ e PPGSND. E-mail: thiago.vieira@ufopa.edu.br
} 
aimed at the social needs of those women. It is imperative that the public authorities develop an active posture based on the social need, making them more comprehensive to the point of serving all people who are part of that association and/or rural communities in the region. Thus, extensive and egalitarian policies must be proposed, discussed and implemented in an attempt to respect the dignity of the human person. In terms of organization, these policies should also value the process of social organization of farmers, providing inclusion within the association and interest of other women to join AMABELA. Women's social movements are responsible for accessing information about their rights.

Keywords: Amazonia; social rights; women; social organization.

\section{Introdução}

Os movimentos sociais nos últimos vinte anos passaram a ser reconhecidos politicamente na Amazônia, esses movimentos foram fortalecidos a partir da década de 1990, consequência da ECO-92, ocasião em que vários acordos financeiros foram firmados e, os recursos advindos dessas parcerias foram distribuídos para algumas organizações sociais, principalmente as localizadas na Amazônia (Lacerda, 2013).

Dentro desse cenário, foram surgindo organizações sociais genuinamente feministas, eram organizações sem recursos, que se tornaram mais consistentes por meio de Organizações Não-Governamentais (ONGs), sendo estas efetivadas com o intuito de colaborar com o desenvolvimento dos movimentos sociais de mulheres e cooperar no processo de sensibilização de políticas públicas direcionadas para o gênero feminino (Deere, 2002). No contexto da Amazônia, esses movimentos sociais surgiram por influência da igreja católica, responsável por denunciar quem desrespeitasse os direitos dos cidadãos, pois o governo militar (1964 a 1985) tentava esconder as manifestações da sociedade civil organizada (Lacerda, 2013).

Os sindicatos e organizações existentes naquele período, eram bastante incipientes, ainda não tinham o poder argumentativo suficiente para promover um movimento reivindicatório, mas, apesar dessa organização sindical ser tímida, os grupos religiosos na Amazônia incentivaram a mobilização contra o governo militar. Apesar dos sindicatos e as organizações sociais fazerem parte de uma minoria na Amazônia no período da ditadura militar, ambos conseguiram chamar a atenção do governo para demonstrar um descontentamento em relação às ações do Estado. As organizações sociais de mulheres rurais começaram a ganhar força nessa época, sendo a Igreja Católica uma das grandes incentivadoras desse movimento (Lacerda, 2013).

Nesse sentido, Sen (2000) elucida a importância da voz ativa das mulheres como agentes capazes de influenciar politicamente a sociedade a desenvolver a natureza da discussão pública sobre diversos temas sociais. O estudo enfatiza a importância da mulher no meio social, destacando para a sociedade a proeminência do papel da mulher como força diligente no processo de transformação de uma dada realidade.

Dessa forma, a pesquisa abordou o conjunto de políticas públicas que as trabalhadoras rurais mais se dedicam a reivindicar. Segundo os estudos de Heredia e Citrão (2006), as mulheres rurais, possuem condições precárias de acesso às políticas públicas para a efetivação dos seus direitos. Por isso, buscouse analisar quais os direitos sociais as agricultoras familiares da Associação de Mulheres Trabalhadoras Rurais do município de Belterra-Pará (AMABELA) têm acesso. A pesquisa foi aprovada pelo Comitê de Ética 
em Pesquisa da Universidade Estadual do Estado do Pará (Uepa), campus XII Tapajós, por meio do Parecer Consubstanciado número 3.261.586.

\section{Perfil socioeconômico das associadas da AMABELA}

Quanto ao perfil socioeconômico das associadas da AMABELA, verificou-se que quanto à idade das agricultoras, elas tinham entre 18 a 62 anos, sendo que a média de idade foi de 47 anos. Além disso, $75 \%$ são casadas; $10 \%$ são viúvas; $5 \%$ separadas; $5 \%$ solteiras e, $5 \%$ vivem em união estável; das entrevistadas $80 \%$ são mães e $20 \%$ não têm filhos. Quanto à escolaridade, $5 \%$ têm o nível superior incompleto; $45 \%$ concluíram o ensino médio; $35 \%$ concluíram o ensino fundamental e $15 \%$ possuem o ensino fundamental incompleto.

Resultado este que se diferencia do obtido por Brilho (2015) no tocante a idade, ao estudar o Movimento de Mulheres das llhas de Belém-Pará (MMIB). Nessa pesquisa, Brilho constatou que a faixa etária das associadas do MMIB é de 15 a 30 anos, correspondendo a 43\%; na faixa etária de 31 a 40 anos (21\%); e 41 a 50 anos (21\%). Observa-se que o número maior de associadas se concentra na menor faixa etária de idade.

A autora também destaca o estado civil das associadas, em que a união consensual/amasiada corresponde a $32 \%$, casadas $29 \%$, solteiras com filhos $15 \%$, solteiras sem filhos $12 \%$, viúvas $9 \%$ e divorciadas $3 \%$, em relação ao grau de instrução formal, cerca de $85 \%$ das mulheres da associação estão estudando, $26 \%$ das associadas têm o nível médio completo e somente $6 \%$ não foram alfabetizadas.

Percebe-se que os resultados encontrados no estudo de Brilho (2015), referente ao estado civil das associadas e a escolaridade, se assemelham com os encontrados em Belterra com a Amabela, em que a maioria das entrevistadas é de casadas ou que vivem em união consensual/amasiada e a escolaridade da maioria é o nível médio completo.

Santos (2018) também estudou um grupo de mulheres rurais que faziam parte do Programa de Aquisição de Alimentos (PAA) na Região Metropolitana de Santarém-Pará. A autora entrevistou 26 delas (oito pertencentes ao município de Belterra, sete de Mojuí dos Campos e 11 de Santarém), mostrando que quanto à idade das entrevistadas a média era de 44,2 anos; resultado este que se aproxima da média de idade encontrada na Amabela.

Quanto ao estado civil das mulheres do PAA, a autora supracitada constatou que $50 \%$ das vivem em união estável, $34,6 \%$ são casadas e $15,4 \%$ são solteiras, separadas e viúvas. Os resultados relacionados ao estado civil estudado por Santos (2018), também se assemelham com o encontrado na Amabela e os encontrados na tese de Brilho (2015).

Santos (2018) apresentou também como resultado da sua pesquisa o nível de escolaridade das cadastradas no PAA, e cerca de $50 \%$ delas possuíam o ensino fundamental incompleto; $34,6 \%$ o ensino médio completo, deste $15,4 \%$ não chegaram a concluir o médio. A autora enfatiza que todas as entrevistadas por sua pesquisa, detinham conhecimento escolar, resultado este, que se coaduna com o mesmo encontrado na Amabela.

Ressalta-se que este programa de compras institucionais é de relevante importância para a agricultura familiar, apresentando alternativas econômicas para a permanência destes trabalhadores e trabalhadoras no campo, além de minimizar a dependência da comercialização da produção familiar à atravessadores (Azerêdo, 2020). 
No que tange às vendas dos produtos agrícolas, as associadas da Amabela que participaram da pesquisa, informaram que a renda obtida girava de $R \$ 40,00$ a $R \$ 800,00$ mensais, com média de $R \$ 385,00$ a partir da venda dos produtos da agricultura.

Com base nas entrevistas realizadas, percebeu-se que a renda obtida pelas associadas com a venda dos produtos cultivados e produzidos variava em função de uma série de fatores, sendo a sazonalidade um importante fator, vez que, ao longo do ano, os períodos da safra de cada produto cultivado influenciam na renda obtida em cada mês, sendo maior na safra e menor na entressafra.

Com relação às questões organizacionais, todas as associadas desenvolvem atividades dentro da associação. Dentre as associadas, $75 \%(n=15)$ participam da comercialização do que é produzido em sua propriedade; $20 \%(n=4)$ participam do processo da colheita; $80 \%(n=16)$ fazem o plantio das culturas vegetais; $25 \%(n=5)$ desenvolvem atividades no artesanato e somente $10 \%(n=2)$ dedicam-se à criação de pequenos animais.

As organizações sociais se constituem em um movimento de busca de alternativas e superação da situação de desemprego, visando a geração de renda (Milani, 2020). No caso da Amabela, como a associação norteia suas atividades pelos princípios da Agroecologia, o que elas levam mais em conta não é quanto se lucra com a venda, mas o que se produziu para o consumo familiar, e pelo excedente que é comercializado, devendo ser de qualidade.

Para ampliar a comercialização do excedente da produção da Amabela, no ano de 2016, a associação passou a fazer parte do projeto "Incubadora de Empreendimentos Solidários" da Universidade Federal do Oeste do Pará (UFOPA), segundo Silva et al. (2016), o respectivo projeto atuava desde 2013 em colaboração à agricultura familiar, com as associações e as cooperativas, e por meio desse projeto, as mulheres da Amabela passam a participar da "Feira do Produtor Rural", espaço que a universidade destinava para os agricultores e agricultoras comercializarem suas produções. Para além das vendas que o projeto vem fomentando, elas também contavam com auxílio contábil, para mensurar o quanto estavam tendo de retorno com a comercialização dos produtos (Ufopa, 2016).

Siliprandi (2015) observa que as mulheres computam tudo que entra para compor a renda familiar, não somente o lucro com a venda dos produtos, mas o que se deixou de gastar, pelo fato de terem aqueles produtos disponíveis nos seus quintais. Vieira et al. (2012) identificaram ao estudarem quintais do município de Bonito-PA, que grande parte das culturas cultivadas são para o autoconsumo, contribuindo com a produção de alimentos para a família, diminuindo os custos de aquisição de alimentos no mercado local.

Merece destaque a Associação das Mulheres Produtoras de Polpa de Fruta (AMPPF), que segundo Morgado (2018), a associação foi criada em São Félix do Xingu, região Sudoeste do Pará, e assim como a Amabela, a AMPPF também comercializa seus produtos, diferindo na medida que esta associação foi criada para a comercialização somente de polpas de frutas, ao passo que no início, essa venda servia para complementar a renda familiar, com o tempo, passou a ser a renda principal da família.

Diante do exposto, apesar das vendas dos produtos cultivados pelas associadas da Amabela não apresentarem um valor expressivo, conforme os dados das entrevistas, mas o fato delas estarem desenvolvendo atividades agrícolas baseadas nos princípios agroecológicos, tem valor imensurável. Para Chaves et al. (2020), populações rurais da Amazônia, por terem suas vidas estritamente relacionadas com o meio ambiente, acabam por utilizar alternativas sustentáveis de uso da natureza, a fim de garantir sua subsistência, reprodução física, social e cultural.

Além disso, esta produção contribui para diminuir a dependência de compra de determinados produtos ou quantidades destes no mercado local. Para Grisa e Schneider (2008), a produção para o consumo familiar constitui-se em uma forma de economizar recursos financeiros, sobretudo uma importante fonte de segurança alimentar, pelo acesso e qualidade dos alimentos. 
Santos et al. (2019) destacam que é de relevante importância, para a academia e a gestão governamental, conhecer o processo produtivo adotado por agricultoras familiares, vez que possibilita obter informações quanto às demandas e desafios destas mulheres, o que auxiliaria na construção de políticas públicas diferenciadas.

\section{Mulheres da AMABELA e o acesso às políticas públicas}

As agricultoras tiveram oportunidade de falar sobre a existência de políticas públicas que são executadas no âmbito da associação e que são direcionadas às associadas. Seis perguntas foram utilizadas observando os princípios da pertinência e exaustividade, preconizados pela técnica Análise de Conteúdo. Bardin (2011) elucida detalhadamente as regras que precisam ser cumpridas na pré-análise, estas contam também com outras etapas que necessitam ser analisadas pelo pesquisador, para que se possa chegar a um resultado consistente da pesquisa.

A primeira pergunta questionou a existência de políticas públicas direcionadas para as associadas, observou-se que $55 \%$ das entrevistadas desconhecem a presença de políticas públicas direcionadas para a associação; $40 \%$ afirmaram não ter políticas públicas, $5 \%$ destacaram uma política que prioriza a alimentação por meio dos princípios da Agroecologia e, também as políticas de orientações que tratam da questão da violência doméstica.

O desconhecimento da existência de políticas públicas pode ser algo relacionado com a falta de acesso a essas políticas. De acordo com Heredia e Cintrão (2006), o acesso das mulheres às políticas públicas ainda é bastante descontínuo, apesar de terem conquistado os seus direitos sociais, estes reconhecidos na Constituição Federal de 1988. Ainda assim, muitas não conseguem visualizar esses direitos, podendo apresentar em algumas circunstâncias, o próprio desconhecimento em relação às políticas públicas existentes.

Araújo (2014), ao desenvolver sua pesquisa com mulheres rurais do distrito de Maria Quitéria, na Bahia, constatou que as políticas públicas existentes para a área rural são políticas emergenciais, atenuantes, e não são políticas estruturantes e permanentes. Esse fato observado pela autora, pode ser uma das causas do desconhecimento das associadas da Amabela em relação às políticas públicas direcionadas ao desenvolvimento da agroecologia e, também das voltadas às instruções quanto a violência doméstica.

A seguir, as associadas foram indagadas se o fato delas estarem associadas, facilitou o acesso à educação e por quê? Pode-se constatar que $85 \%$ delas consideraram que o fato de estarem na associação possibilitou melhorias no acesso à educação não formal, uma vez que a associação viabiliza, por meio de parcerias, a oferta de cursos de capacitação. Contudo, apenas 15\% das associadas informaram não ter tido acesso aos cursos articulados pela associação.

Aguiar (2016) afirma que a participação política e as intervenções dos movimentos de mulheres rurais no espaço público, corroboram com o reconhecimento delas como sujeito de direito, essa participação feminina permitiu que algumas demandas fossem atendidas, como exemplo têm-se a questão da educação não formal. O processo de fortalecimento da educação não formal nas associações de mulheres faz parte de uma das conquistas dos movimentos rurais de mulheres. Dentro das redes associativas da sociedade civil, segundo Gohn (2006), a educação não formal:

Designa um processo com várias dimensões tais como: a aprendizagem política dos direitos dos indivíduos enquanto cidadãos; a capacidade dos indivíduos para o trabalho, 
por meio da aprendizagem de habilidades e/ou desenvolvimento de potencialidades; a aprendizagem e exercício de práticas que capacitam os indivíduos a se organizarem com objetivos comunitários, voltados para a solução de problemas coletivos cotidianos (Gohn, 2006, p. 28).

A autora enfatiza a importância da educação não formal para o desenvolvimento da cidadania, contribuindo para estimular os conhecimentos essenciais para as organizações sociais, e para o andamento das atividades desempenhadas nas associações e com a interação social dos indivíduos envolvidos. O resultado da pesquisa de Gohn (2010) coaduna-se com a tese de Bendrath (2014), ao estudar "Educação não formal a partir dos relatórios da Unesco", o autor destaca que os princípios básicos da educação não-formal são caracterizados pela troca de informações, pelo respeito e, principalmente, pelo interesse mútuo dos participantes.

Dessa forma, percebe-se que a educação não-formal é de suma importância, ela não só capacita os envolvidos, como também trabalha com as relações sociais, com a troca de conhecimentos e auxilia com o desenvolvimento do capital humano das associadas.

Araújo (2014), ao desenvolver sua pesquisa sobre sentimentos da escolarização para mulheres no meio rural de Feira de Santana, na Bahia, aduz a importância da educação escolar para minimizar as desigualdades sociais, afirmando que a escolarização é um meio de trazer para as pessoas desprovidas de recursos uma oportunidade. Assim, a autora destaca a realidade do meio rural na educação do distrito Maria Quitéria (Feira de Santana-BA), enfatizando a necessidade de políticas públicas efetivas para as mulheres rurais, de caráter permanente, para que possam atender as demandas educacionais existentes e de fato transformar a realidade social delas e de todas as pessoas que estão inseridas nesse contexto educacional.

Verifica-se, assim, o quanto a educação tem o poder de modificar a realidade das pessoas, seja a nãoformal como a formal, o fato é que a educação é de suma importância para o desenvolvimento das relações sociais. A educação trará modificações positivas para a sociedade e será sempre responsável pela redução das desigualdades sociais existentes. A pesquisa com as associadas da Amabela em relação ao acesso à educação demonstrou que a educação não-formal se destaca dentro da associação, tendo um papel significativo para as associadas, pois os cursos ofertados contribuem para que elas possam desenvolver suas atividades com mais competência e conhecimento. Algumas associadas destacaram que gostariam de ter acesso a educação formal. O direito à educação vem assegurado na Constituição Federal de 1988, no seu artigo 205, que diz que a educação é um direito de todos, cabendo ao Estado e a família possibilitar meios para que ela seja promovida (BRASIL, 1988).

Outro questionamento que foi levantado na entrevista referiu-se às políticas de previdência social, $95 \%$ das entrevistadas relataram que a associação orienta a sindicalização e disponibiliza uma declaração que comprova que são associadas, e apenas $5 \%(n=1)$ desconhecem essas orientações. As orientações que as mulheres da Amabela recebem são divulgadas em reuniões, nas quais todas as associadas são convidadas a participarem, mas muitas não participam rotineiramente das atividades da associação, por residirem distante do local onde geralmente se reúnem.

No que tange a questão da previdência social, Aguiar (2016) expressa que quanto aos direitos sociais, o direito à previdência social se tornou possível para as trabalhadoras rurais, devido a participação delas na elaboração do texto constitucional de 1988. Na ocasião do Encontro Nacional de Mulheres, em 26 de agosto de 1986, elas escreveram uma carta pedindo pela democracia e destacaram os seus direitos, solicitando que estes fossem apreciados pelo legislador constituinte. Brumer (2002) afirma que a Carta Magna de 1988 e, as Leis 8.212 e 8.213 , ambas de 1991, consolidaram no ordenamento jurídico brasileiro, o direito de todos os grupos à previdência social, assim, as mulheres trabalhadoras rurais também passaram a fazer parte 
desse grupo de pessoas com acesso aos direitos previdenciários. A autora expressa que a previdência rural tem suas particularidades em relação à urbana, sendo a primeira peculiaridade a forma de contribuição urbana, feita sobre os salários e rendas recebidos, enquanto a forma de contribuição dos trabalhadores e trabalhadoras rurais incide sobre o valor da produção que é vendida, forma esta que já era praticada antes das respectivas legislações.

Outro ponto de diferenciação entre a previdência rural e a urbana trata-se da idade limite para aposentadoria de homens e mulheres trabalhadores e trabalhadoras rurais, sendo 60 anos para homens e 55 anos para mulheres, e a idade mínima para a previdência urbana ficou em 65 anos para os homens e 60 para as mulheres. Deste modo, a previdência social para as mulheres rurais foi regulamentada pela Constituição Federal de 1988 e posteriormente pelas leis ordinárias, possibilitando igualdade de tratamento previdenciário entre homens e mulheres e entre todas as pessoas. De uma perspectiva mais ampla, Sueli Carneiro (2003) destaca o fato de que o movimento feminino no país, considerado por sua atuação um dos mais importantes do mundo, marcou profundamente os caminhos do texto constitucional de 1988. A autora conclui dizendo que com $80 \%$ de suas demandas incluídas na Constituição Federal, foram modificadas por meio dos movimentos femininos, transformando profundamente o "status" jurídico no Brasil.

Recentemente a previdência social passou por uma reforma, a Emenda Constitucional n 103/2019, alterou alguns artigos que tratam da previdência social, mas quanto aos trabalhadores rurais não houve mudanças, segundo o artigo 201, $\S 7^{\circ}$, inciso II, dispõe que a idade mínima continua a mesma, 55 para as mulheres e 60 para os homens (Brasil, 2019). Percebe-se que a Emenda Constitucional não trouxe novos benefícios para as trabalhadoras rurais, mas manteve os direitos previdenciários já adquiridos por elas.

Quando questionadas sobre quais as maiores necessidades de acesso às políticas públicas, as agricultoras da Amabela mostraram que a saúde é a principal demanda, esse resultado fica evidente quando se destaca que $85 \%$ das entrevistadas mostraram ser a área de maior importância para elas; seguido pelo tema da educação $30 \%$.

O tema trabalho também foi abordado por $15 \%$ das respostas e as associadas também destacaram a importância de terem acesso às políticas públicas direcionadas ao transporte $5 \%$, o que permitiria maior frequência e participação das associadas em atividades da associação.

Para elas, a falta de acesso às políticas relativas à saúde causa desconforto, pois elas demonstraram que necessitam de informações relacionadas à saúde da mulher, destacando que por serem trabalhadoras rurais e desenvolverem atividades na agricultura familiar, estão vulneráveis a contrair vários tipos de doença.

O direito à saúde consta positivado na Constituição Federal de 1988, que expressa em seu artigo 196, que a saúde "é um direito de todos e dever do Estado", este deve garantir esse direito por meio de políticas sociais e econômicas, que objetivem reduzir os riscos de doenças e seus agravos, para todas as pessoas, sem distinção. Porém, percebe-se com o resultado da pesquisa, que o direito à saúde necessita de políticas mais universais e integrais, que garantam equidade, de modo que todas as pessoas consigam ter acesso de qualidade e sem distinção.

Ainda nesse contexto, Wolff (2015) nos lembra que o direito à saúde passa a ser universal a partir do artigo 196 da Carta Magna, destacando as diretrizes dispostas no texto constitucional, em que expressa que o direito à saúde deve ser descentralizado, com atendimento integral, priorizando as atividades preventivas e a participação comunitária.

Com relação a essas políticas públicas direcionadas à saúde da mulher, Britto (2014) explica que no início da década de 1980, elas intensificaram a pauta deste tema em suas reivindicações, e o governo brasileiro, para atender as demandas dos movimentos sociais femininos, aprovou o Programa de Assistência Integral à Saúde da Mulher (PAISM). 
A relevância desse programa foi bastante significativa, Osis (1998) destaca que a abordagem desse programa abrange não só à saúde reprodutiva da mulher, mas também a integração da saúde da mulher dentro do contexto social. O autor enfatiza que o PAISM foi o primeiro programa a tratar da saúde reprodutiva e integral da mulher, a nível mundial, mas apesar desse pioneirismo, o programa não atende ao que se propôs, por isso, vem sendo tema de discussões, uma vez que sua implementação dentro do sistema público de saúde encontra-se deficitária.

Segundo o Ministério da Saúde (2019), a Política Nacional de Atenção Integral à Saúde da Mulher, unida com os estados e municípios vêm desenvolvendo políticas públicas preferenciais para a melhoria dos serviços nas áreas da saúde sexual e reprodutiva da mulher; com uma atenção maior à obstetrícia, oncologia, ginecologia, climatério, considerando a situação de vulnerabilidade da mulher no meio social. Essa deficiência no acesso às políticas públicas de saúde da mulher atinge todas as idades do público feminino.

Estudos de Farah (2004) apontam que desde os anos de 1970, especialmente nos centros urbanos, ocorreu uma luta pela democratização dessas políticas, e os programas de saúde direcionados para mulheres, em sua maioria, são resultados de políticas nacionais, e não resultam de movimentos sociais locais, isso do ponto de vista da implementação dificulta ainda mais o acesso aos grupos de mulheres que vivem em condição de vulnerabilidade social.

Com relação ao trabalho na agricultura, as entrevistadas foram unânimes ao afirmarem que possuem orientações técnicas para o desenvolvimento do trabalho agrícola. Destaca-se que $60 \%$ delas disseram que essas orientações ocorrem conforme a demanda; $25 \%$ alegaram que essa constância é mensal, $5 \%$ acredita que é semestral e 10\% desconhecem a frequência dessas orientações. As associadas citaram que as orientações são feitas por meio da Empresa de Assistência Técnica e Extensão Rural (Emater-Pará), a qual possui um escritório local na área urbana do município de Belterra.

Segundo elas, a respectiva empresa desenvolve ações associadas às políticas públicas que corroboram com o meio ambiente rural, prestando orientações técnicas sobre as plantações de culturas; sobre o controle de pragas com a utilização de insumos naturais; e doação de sementes para as associadas; e para além dessas atividades, a Emater visa contribuir com fortalecimento da agricultura familiar nesta região.

Siliprandi (2015) destaca que as entidades de assistência técnica podem contribuir com o desenvolvimento do trabalho na agricultura, uma vez que as orientações prestadas por estas instituições são fundamentais, à medida que agregam o conhecimento científico ao empírico, visando contribuir para melhoria da vida rural. Ramos (2014) ressalta que órgãos governamentais, como a Emater, executam políticas públicas direcionadas para orientação e técnicas agrícolas objetivando especializar o trabalho desempenhado na agricultura familiar.

Colaborando com tal entendimento, Cruz (2017) expressa que a Política Nacional de Assistência Técnica e Extensão Rural (Pnater-2010), como política pública não deixa de abranger os direitos sociais, trazendo como fundamento a probabilidade de construir uma autenticidade no campo, relacionada dentro do panorama agroecológico, sustentável e emancipador. Para este autor, essa política vai além do assistencialismo, ela atua alargando os conceitos no meio rural, reconhecendo as mulheres do campo como trabalhadoras rurais.

Ao se tratar de assistência técnica para o desenvolvimento das atividades na Amabela, outra indagação bastante pertinente que se levantou nesse estudo, foi exatamente sobre os recursos financeiros que a associação disponibiliza para manter todo o trabalho das associadas. No que tange a esses recursos financeiros para o desenvolvimento do trabalho das associadas da Amabela, tem-se que $75 \%$ relataram que a fonte de recursos financeiros da associação, se dá por meio de projetos elaborados visando à captação de recursos. 
Esse resultado demonstra que o recurso só chega até a associação mediante projetos, de modo que a associação não conta com recursos fixos. Nead (2005) destaca ainda como possibilidade o acesso a recursos financeiros, o Programa Nacional de Fortalecimento da Agricultura Familiar (Pronaf), que por meio da linha de crédito Pronaf Mulher, elas podem ter acesso a esses recursos, a partir de projetos aprovados pela instituição financeira legal.

Cerca de $75 \%$ das entrevistadas mencionaram que os recursos financeiros que chegam até a Amabela são provenientes do Fundo Dema Mulheres. Este recurso é específico para o fortalecimento de projetos coletivos de mulheres do Baixo Amazonas, sendo que o acesso a esse fundo acontece também, por meio de projetos (FUNDO DEMA, 2014). O Fundo Dema Mulheres, objetiva tornar mais robusto os grupos femininos que lutam pela equidade de gênero, promovendo a autonomia das mulheres e fortalecendo as suas organizações por intermédio do suporte financeiro, disponibilizado para execução dos projetos desempenhados no âmbito da associação.

A análise do acesso a recursos financeiros para fomento da atividade agroecológica das associadas foi a última questão objeto das entrevistas realizadas. De fato, a análise foi fundamental para a percepção da realidade das entrevistadas, contribuindo para a identificação das políticas públicas. A partir das entrevistas realizadas, observou-se que as associadas da Amabela não usufruem de políticas públicas específicas, mas enquanto associadas elas têm a possibilidade do acesso às políticas desenvolvidas pelos órgãos públicos e ONGs que apoiam o associativismo. $O$ fato de estarem associadas corrobora para que elas adquiram mais informações sobre os seus direitos enquanto cidadãs, para reivindicarem junto ao poder público a efetivação e implementação desses direitos.

De acordo com Aguiar (2016), foi na década de 1980 que os movimentos de mulheres se fortaleceram principalmente no campo. A principal conquista delas nos movimentos rurais nessa época, segundo Deere (2004), foi o reconhecimento como trabalhadoras rurais, reconhecimento que possibilitou às ruralistas tivessem acesso aos direitos trabalhistas e previdenciários.

Heredia e Citrão (2006) apontam que apesar das conquistas femininas em relação às políticas públicas para as trabalhadoras rurais, estas ainda são exíguas, diante da grande desigualdade existente. Afirmam ainda, que os movimentos sociais femininos de trabalhadoras rurais continuam desempenhando um papel fundamental nessa conquista, por isso, a importância desses movimentos rurais formarem organizações sociais.

Destarte, as organizações sociais de mulheres rurais vêm a cada ano se fortalecendo, com o apoio de diversos órgãos, estes fundamentam-se nas normas internacionais de Direitos Humanos e nas normas internas, que foram consolidadas ao longo da história. Para Piovesan (2012), essas normas internacionais são de suma relevância, pois são deveres do Estado, este responsável para desenvolver medidas por meio de políticas públicas que possibilitem o acesso de todas a esses direitos.

\section{Conclusão}

O estudo identificou que as mulheres da Amabela acessam às políticas públicas de forma insuficiente, e têm acesso às políticas de caráter universalista, sem escopo interseccional, não sendo, portanto, detectado, na pesquisa, políticas públicas específicas para as associadas. As políticas públicas existentes são frutos das conquistas no decorrer da história dos movimentos sociais de mulheres rurais, que impulsionaram uma série de acordos internacionais de direitos humanos, estes por sua vez passaram a fazer parte do direito interno dos países signatários. Os direitos que necessitam de políticas públicas para serem de fato 
implementados são exatamente os direitos sociais, e continuam impotentes nos seus efeitos dentro da associação, ao ponto de as associadas não perceberem a existência de qualquer conjunto de políticas públicas que possam mitigar as desigualdades de gênero que operam na institucionalidade.

As associadas visualizam de forma clara a efetivação e implementação de políticas públicas relacionadas ao desenvolvimento do trabalho na agricultura, por meio de orientações técnicas. As integrantes da Amabela são instruídas quanto ao sindicalismo e à previdência social, e contam com algumas parcerias que possibilitam o acesso à educação não-formal, materializadas por cursos de capacitação direcionados para o desempenho do trabalho das associadas.

No que se refere às políticas públicas que elas ainda não conseguem ter acesso de forma eficiente, destacam-se a política de saúde da mulher, e uma vez associadas, cria-se a possibilidade de terem acesso a essa política. E sobre políticas de saúde da mulher, as associadas sempre fazem discussões sobre esse tema em suas reuniões e reivindicam essa política nos movimentos sociais.

Por estarem associadas, o acesso a algumas políticas públicas foi possibilitado, situação que acontece por meio de parcerias com órgãos governamentais e algumas ONGs, que desenvolvem trabalhos dentro do contexto de vida e trabalho das mulheres agricultoras. As associadas já conseguiram se destacar com o desenvolvimento dos seus trabalhos, como na plantação de culturas respaldadas pelos princípios agroecológicos; no artesanato; na criação de pequenos animais; e ainda participam por meio da sua diretoria de movimentos sociais femininos rurais na região.

É necessário salientarmos a importância organização social na Amazônia, principalmente quando se trata de associações de mulheres. Estas organizações desempenham papel fundamental dentro da associação, da comunidade, e até em escala familiar, dando vez e voz a esse grupo vulnerável, compartilhando conhecimento, participação econômica, autonomia, valorização do trabalho feminino e corrobora para que elas sejam as protagonistas de suas próprias histórias, sendo empoderadas e emancipadas.

Dentro dessa perspectiva, este estudo não teve o escopo de esgotar o tema. Espera-se que a presente pesquisa seja utilizada de forma a instigar novos estudos sobre o acesso das políticas públicas para as mulheres rurais na Amazônia.

\section{Referências:}

Aguiar, V. V. P. (2016). Mulheres rurais, movimento social e participação: reflexões a partir da marcha das margaridas. Rev. Política e Sociedade, 15: 261-295.

Araújo, V. A. C. (2014). Os sentidos da escolarização para mulheres no rural de Feira de Santana/Bahia: narrativas de trajetórias e sonhos de mulheres da EJA. Dissertação Feira de Santana: Universidade Estadual de Feira de Santana.

Azerêdo, R. F. (2020). Cooperação agrícola e produção de alimentos na Amazônia brasileira: notas introdutórias em tempos de Covid-19. Revista NAU Social,11(21): 427-439.

Bardin, L. (2011). Análise de conteúdo. São Paulo: Edições 70.

Bendrath, E. A. (2014). A educação não-formal a partir dos relatórios da UNESCO. Tese. Presidente Prudente: Universidade Estadual Paulista Júlio de Mesquita Filho, Faculdade de Ciências e Tecnologia.

Brasil. Reforma da Previdência Social. Emenda Constitucional n 103, de 12 de novembro de 2019. 
Presidência da República. Constituição (1988). Constituição da República Federativa do Brasil de 1988. Brasília, DF, 1988.

Brilho, S. S. Q. C. (2015). Dinâmica econômica e social na Amazônia rural: o Protagonismo do Movimento de Mulheres das Ilhas de Belém-MMIB (PA). Tese. Campinas: Universidade Estadual de Campinas.

Brumer, A. (2002). Previdência social rural e gênero. Sociologias, 7: 50-81.

Carneiro, S. (2003). Mulheres em movimento. Estudos avançados, 17: 117-133.

Chaves, M. P. S. R.; Rodrigues, D. C. B.; Nascimento, C. F. P.; Pedrosa, E. B.; Silva, T. S. (2020). Sustentabilidade \& qualidade de vida: práticas sustentáveis de saúde em comunidades ribeirinhas no Amazonas. Revista de Políticas Públicas, 24(1): 265-285.

Cruz, J. N. (2017). Política nacional de assistência técnica e extensão rural: percurso histórico enquanto política pública, possibilidades e desafios. In: JORNADA INTERNACIONAL DE POLÍTICA PÚBLICA DA UFMA, 8. São Luis, Anais. p. 22-25. Maranhão: UFMA. Disponível em: $<$ www.joinpp.ufma.br/jornadas/joinpp2017/pdfs/eixo10/politicanacionaldeassistenciatecnicaeextensaorural >. Acesso em: 30 jun. 2019.

Deere, C. D. (2002). Diferenças regionais na reforma agrária brasileira: gênero, direitos à terra e movimentos sociais rurais. Estudos Sociedade e Agricultura, 18: 112-146.

Deere, C. D. (2004). Os direitos da mulher à terra e os movimentos sociais rurais na reforma agrária brasileira. Revista Estudos Feministas, 12(1): 175-204.

Farah, M. F. S. (2004). Gênero e políticas públicas. Revista Estudos Feministas, 12(1): 47-71.

Fundo Dema. (2014). Quem Somos: Dema Mulheres. Disponível em: <http://www.fundodema.org.br>. Acesso em: 20 nov. 2018.

Gohn, M. G. (2010). Educação não formal e o educador social atuação no desenvolvimento de projetos sociais. São Paulo: Cortez; Coleção Questões da Nossa Época; Disponível em: <revista.cesgranrio.org.br/index.php/metaavaliacao/>. Acesso em: 07 de set. 2019.

Gohn, M. G. (2006). Educação não-formal na pedagogia social. In: CONGRESSO INTERNACIONAL DE PEDAGOGIA SOCIAL, 1. Proceedings online. Faculdade de Educação, Universidade de São Paulo. Disponível em: <http://www.proceedings.scielo.br/scielo.php?script=sci_arttext\&pid=MSC0000000092006000100034\&lng= en\&nrm=abn>. Acesso em: 22 ago. 2019.

Grisa, C.; Schneider, S. (2008). "Plantar pro gasto": a importância do autoconsumo entre famílias de agricultores do Rio Grande do Sul. Revista de Economia e Sociologia Rural, 46(2): 481-515.

Heredia, B. M. A.; Citrão, R. P. (2006). Gênero e acesso a políticas públicas no meio rural brasileiro. Rev. Nera, 9(8): 1-28.

Lacerda, P. M. (2013). Movimentos sociais na Amazônia: articulações possíveis entre gênero, religião e Estado. Boletim do Museu Paraense Emílio Goeldi. Ciências Humanas, 8(1): 153-168.

Milani, A. M. R. (2020). Economia Solidária, desenvolvimento local e crise da Covid-19: a experiência das mulheres artesãs em Alagoas - Brasil. Revista NAU Social, 11(21): 293-307.

Ministério da Saúde. (2019). SUS cuida da mulher em todas as fases da vida. Disponível em: $<$ www.saude.gov.br/noticias/agencia-saude/45286-sus-cuida-da-mulher-em-todas-as-fases-da-vida>.

Acesso em: 23 de ago. 2019. 
Morgado, A. (2018). Mulheres do campo criam associação para comercializar polpa de fruta. Disponível em: $<w w w$.imaflora.blospot.com/2018/01/mulheres-do-campo-criam-associacao-para.html>. Acesso em: 22 ago. 2019.

Nead - Núcleo de Estudos Agrários e Desenvolvimento Rural. (2005). Cirandas do Pronaf mulheres. Brasília: NEAD. Disponível em: <www.reformaagrariaemdados.org.br>. Acesso em: 28 fev. 2019.

Osis, M. J. M. D. (1998). Paism: um marco na abordagem da saúde reprodutiva no Brasil. Cad. Saúde Pública, 14: S25-S32.

Piovesan, F. (2012) Direitos humanos e o direito constitucional internacional. 13 ed. São Paulo: Saraiva.

Ramos, C. P. (2014). Mulheres rurais atuando no fortalecimento da agricultura familiar local. Gênero, 15(1): 29-46.

Santos, Á. O.; Sousa, W. L.; Monte, L. F. O.; Vieira, T. A.; Quaresma, E. S. (2019). O Programa aquisição de alimentos (PAA) na Região Metropolitana de Santarém (Pará): o caso das mulheres agricultoras da COOMAPLAS. Brazilian Journal of Development, 5(7): 11090-11106.

Santos, Á. O. (2018). Cultivando política pública, colhendo autonomia: análise da participação das mulheres agricultoras da região metropolitana de Santarém-PA, no Programa Aquisição de Alimentos-PAA. Dissertação. Santarém: Universidade de Federal do Oeste do Pará.

Sen, A. K. (2000). Desenvolvimento como Liberdade. São Paulo: Companhia das Letras. 221 p.

Siliprandi, E. (2015). Mulheres e agroecologia: transformando o campo, as florestas e as pessoas. Rio de Janeiro: Editora UFRJ.

Silva, H. W. S.; Barp, W. J. (2016). Discurso e Conflito dos Movimentos Sociais Rurais na Amazônia: os posseiros e os sem terra. In: Encontro Nacional da Anppas, 4. Anais. Disponível em: <www.anppas.org.br/>. Acesso em: 29 dez. 2018.

Ufopa. (2016). Universidade Federal do Oeste do Pará. Relatório Anual de Atividades: Incubadora de Empreendimentos Solidários. Santarém: Ufopa.

Vieira, T. A.; Rosa, L. S.; Santos, M. M. L. S. (2012). Agrobiodiversidade de quintais agroflorestais no município de Bonito, Estado do Pará. Rev. Cienc. Agrar., 55(3): 159-166.

Wolff, M. P. (2015). Direitos Sociais: fundamentos e política de implementação. 1 ed. São Paulo: Estúdio Editores.com. 